\title{
Ideologia e relações de gênero: um estudo de recepção das propagandas de prevenção da AIDS
}

\author{
Ideology and gender relations: a reception \\ study about AIDS prevention campaigns
}

Adriane Roso ${ }^{1}$

1 Faculdade de Psicologia, Programa de Pós-Graduação em Psicologia, Pontifícia Universidade Católica do Rio Grande do Sul. Avenida Ipiranga 6681, Porto Alegre, RS 90619-900, Brasil.

\begin{abstract}
This article refers to a reception research of seven television prevention campaigns, done in South Brazil - Porto Alegre, Rio Grande do Sul, with 38 women, ages 18-51 years old, from low-income class. The sample was divided in two groups: women that don't participate in groups that fight against AIDS/HIV and women that participates in groups that fight against AIDS/HIV. Based in a qualitative framework, the Depth Hermeneutic and the Feminist Theory were employed in order to study the ideology and gender relations underneath the campaigns' messages. The results indicate that for both groups of women television is an important source of AIDS related information, although they believe the campaigns do not stimulate the use of condom. While the first group of women agrees and identifies themselves with the majority of messages and images within the campaigns, the second group perceives that behind the messages the voice of the ideology operates, throughout a variety of strategies, to create and to establish relations of domination.
\end{abstract}

Key words Acquired Immunodeficiency Syndrome; Interpersonal Relations; Television

Resumo Este artigo refere-se a um estudo de recepção de sete propagandas de prevenção da AIDS na televisão, feito no sul do Brasil, em Porto Alegre, Rio Grande do Sul, com 38 mulheres com idades entre 18 a 51 anos, da classe econômica baixa. A amostra foi dividida em dois grupos: mulheres que não participam em grupos que lutam contra a AIDS/HIV e mulheres que participam em grupos que lutam contra a AIDS/HIV. A abordagem é qualitativa, empregando a hermenêutica de profundidade e a teoria feminista a fim de estudar a ideologia e as relações de gênero que perpassam as mensagens das propagandas. Os resultados indicam que para os dois grupos de mulheres a televisão é uma importante fonte de informações relacionadas à AIDS, embora elas acreditem que as propagandas não estimulam o uso do preservativo. Enquanto o primeiro grupo de mulheres concorda e se identifica com a maioria das mensagens e imagens das propagandas, o segundo grupo percebe que, por trás das mensagens, a voz da ideologia opera, através de uma variedade de estratégias, para criar e estabelecer relações de dominação.

Palavras-chave Síndrome de Imunodeficiência Adquirida; Relações Interpessoais; Televisão 


\section{Introdução}

Vários estudos têm indicado que os meios de comunicação de massa, ancorados em uma ideologia patriarcal e capitalista, (re)produzem relações assimétricas de gênero - relações de dominação de gênero - as quais moldam e reificam os papéis sexuais, convertendo-os em estereótipos de gênero (Ang, 1990; Fiske, 1990; Cabruja \& Pujal, 1993; Sancho, 1993; Eisler, 1996; Winship, 1996).

Quando prevenção envolve sexualidade, precisamos conhecer o que está por trás das práticas de risco, para encontrarmos meios de alterar a ideologia dessa prática, e, quando o tema sexualidade liga-se ao tema meios de comunicação de massa, pesquisar fica muito mais complicado. O pesquisador precisa estar atento não somente aos fatos, mas, especialmente, ao som das vozes oprimidas.

Nesta pesquisa, ouvimos as vozes de 38 mulheres, com idades entre 18 e 51 anos, pertencentes à classe baixa, com baixo nível de escolaridade e com parceiro fixo. Vinte e nove mulheres não participam em grupos que estão voltados à prevenção da AIDS, mas fazem parte de grupos pré-existentes: círculo de mães e grupo de trabalho. Nove participam do projeto de Incentivo à Participação Popular na Luta contra as DSTs/AIDS. Denominamos o primeiro grupo de coralistas - principal foco deste estudo - e, o segundo de solistas.

Os nomes coralistas e solistas surgem da idéia de que construir uma pesquisa é, muitas vezes, semelhante a reger um coral. Em um coral, as vozes não são criadas, elas já existem. Podem ser aprimoradas, mas nunca criadas. $\mathrm{O}$ maestro (pesquisador) está ali apenas para incentivá-las a cantar e para regê-las em nome de um conjunto. Em um coral, temos as vozes em coro, que são a grande massa, e as vozes solo, que são as vozes diferentes, que se destacam.

O objetivo do trabalho foi conhecer como essas mulheres vêm percebendo as formas simbólicas - mensagens verbais e visuais - veiculadas pelas propagandas de prevenção da AIDS na televisão, procurando desvelar a existência de possíveis modos e estratégias utilizados pela ideologia patriarcal/capitalista para a reprodução das relações de dominação de gênero.

\section{Metodologia: preparando o coral}

Adotamos uma abordagem teórico-metodológica de pesquisa qualitativa, entendida como aquela capaz de incorporar a questão do significado e da intencionalidade como inerentes aos atos, às relações e às estruturas sociais, sendo as últimas consideradas, tanto no seu advento quanto na sua transformação, como construções humanas significativas (Guba \& Lincoln, 1981, 1985; Minayo, 1992).

A hermenêutica de profundidade (HP) (Thompson, 1995) serviu de suporte metodológico para essa pesquisa. Apoiada no paradigma de pesquisa qualitativa, a HP vem a ser "uma forma de analisar a mídia que é fundamentalmente ideológica e cultural, ou seja, que está preocupada não somente com o caráter significativo das formas simbólicas, mas, também, com a contextualização social das mesmas. Não importa somente o que elas significam, mas como elas significam dentro de determinado contexto social" (Roso, 1998:153-154).

Na HP, o termo ideologia é central e referese às maneiras como "o sentido, mobilizado pelas formas simbólicas, serve para estabelecer $e$ sustentar relações de dominação: estabelecer, querendo significar que o sentido pode criar ativamente e instituir relações de dominação; sustentar, querendo significar que o sentido pode criar e reproduzir relações de dominação através de um contínuo processo de produção e recepção de formas simbólicas" (Thompson, 1995:79).

A análise da ideologia na HP envolve basicamente três fases: análise discursiva, análise sócio-histórica e interpretação/re-interpretação. Neste artigo, priorizaremos a análise discursiva, ou seja, o discurso das coralistas e solistas, colhidos através da técnica do desenho da figura feminina (TDFF), de grupos focais (GF) e de entrevistas individuais (E).

A TDFF vem a ser uma adaptação da técnica de Machover (Draw a Person - DAP), em que solicitamos que se desenhasse uma mulher e fizemos algumas perguntas: "Do que essa mulher gosta?"; "Como é essa mulher?”; "Tem alguma coisa de parecido entre você e ela?"

Em seguida, realizamos cinco grupos focais, organizados segundo Berger (1995) e Debus (1986): três com coralistas e dois com solistas. Os grupos foram homogêneos quanto ao sexo, classe social e local de procedência. Apenas em relação à idade não houve homogeneidade, pois consideramos inadequado alterar a estrutura dos grupos pré-existentes. O fato de elas se conhecerem e estarem familiarizadas a falar em grupo não prejudicou o debate; muito pelo contrário, só o fortaleceu (Roso, 1997).

Após ter estabelecido uma relação de confiança (rapport) nos grupos, foi explicado que seriam mostradas sete propagandas de televisão sobre as quais discutiríamos depois. As propagandas foram passadas duas vezes, na seguinte ordem e assim denominadas: "Hebe", 
"Eu confio”, "Eliakim Araújo”, "Leila Cordeiro”, "Galinha”, "Carnaval" e "Pega - Não Pega". Então, iniciou-se um debate não-estruturado, com questões do tipo: "O que passa na cabeça de vocês quando assistem essas propagandas?"; "O que essas mensagens significam para vocês?”; "O que as mulheres das propagandas têm em comum com vocês?”; etc.

Utilizamos a entrevista de profundidade como um recurso extra de investigação. Foram feitas oito entrevistas individuais, tendo, como estímulo, as mesmas perguntas feitas nos grupos focais. Os dados colhidos foram analisados a partir da articulação entre a hermenêutica de profundidade, que enfatiza os aspectos ideológicos dos meios de comunicação de massa, e a perspectiva feminista, que coloca a mulher no centro de seus estudos. Também recorremos a músicas populares brasileiras para enriquecer nossa interpretação. Porque a música carrega uma função sócio-psicológica significativa na sociedade, pensamos em utilizá-la na pesquisa, como uma ponte entre a literatura acadêmica e a voz reprimida do povo. Extraímos das letras de algumas músicas o que, muitas vezes, não está escrito nos livros, em virtude do conservadorismo positivista que os têm impregnado.

Sumariamente, na análise discursiva procedemos assim: fez-se a leitura flutuante do texto (discurso) de cada grupo/entrevista, colorindo trechos significativos e agrupando temas semelhantes. Os temas foram listados, avaliados e abreviados, formando núcleos de sentido. Esses núcleos propiciaram a formulação de categorias, ou seja, palavras que descrevem mais fielmente os tópicos e que têm algum significado sócio-histórico. A partir da categorização, fizemos inferências e adiantamos interpretações a propósito dos objetivos previstos ou que diziam respeito a outras descobertas inesperadas.

\section{Apresentação dos dados e interpretação/re-interpretação: a melodia dos instrumentos}

Foram criadas as seguintes categorias: Amélia, Moina, Geni, José, Ricardão, AIDS/HIV, Camisinha, Autocuidado e Propagandas. Para escolher os nomes Amélia e Geni, baseamo-nos em músicas populares e na própria fala das mulheres. José e Ricardão foram escolhidos por causa da popularidade desses nomes e o próprio sentido que eles têm para o senso comum. A pergunta que nos fizemos foi: "Qual o nome que está nas músicas, elou na fala do povo, que melhor representa o que estas mulheres estão falando?"
Essa categorização não pretende ser, e nem é, uma ilustração perfeita das percepções dessas mulheres. Tentamos apenas sistematizar e tornar mais visível uma realidade que está em constante construção, onde tudo o que acontece é ininterruptamente re-interpretado. As categorias que apareceram no discurso das coralistas e no das solistas foram basicamente as mesmas. Juntamos as falas dos dois grupos, mas destacamos quando os discursos se diferenciavam.

\section{Amélia (autoconceito das coralistas)}

Ao analisar o discurso produzido pelas coralistas, percebemos que elas são o tipo de mulher que se encaixa dentro das exigências sociais e que vem a ser o tipo mais glorificado para cumprir o papel tradicional de esposa-mãe. Chamamos essa mulher de Amélia, porque esse nome têm tido uma significação marcante em termos de mulher que se coloca em segundo plano, que vive para satisfazer os desejos e as vontades de um homem. A música de Ataulfo Alves e Mário Lago (1994), “Ai que saudades da Amélia”, viva na memória do povo, reforça e valoriza esse tipo de mulher:

“Ah! Meu Deus, que saudade da Amélia, aquilo sim que era mulher

Às vezes passava fome ao meu lado e achava bonito não ter o que comer (...)

Amélia não tinha a menor vaidade, Amélia é que era mulher de verdade"

Elas se autodescrevem como donas-de-casa, trabalhadeiras, organizadas, lutadoras, submissas e alegres. Os prazeres mais importantes em suas vidas são cuidar dos filhos, do marido e da casa. Entre os desprazeres, encontramos barulho, gritos e bagunça dentro de casa.

$\mathrm{O}$ aspecto de submissão, de passividade e de viver para o marido, filhos e casa é o que transformam essas mulheres em "Amélias", segundo as mulheres solistas:

"Se é uma Amélia, vive dentro de casa, tem filho, são casadas (...)”.

"Elas são assim: "Ah, se eu não der, ele vai procurar a outra".

"Sim, elas são assim. A maioria é como a Amélia".

"Tem mulheres que não têm noção, que fazem tudo o que o homem quer".

“(...) é submissa”.

Outra característica muito freqüente é a fidelidade a seus companheiros e o comportamento reservado com homens em geral. No entanto, a maioria dessas mulheres confia apenas em parte nos seus companheiros. É como no ditado popular, que diz para confiarmos desconfiando: 
"Não confio muito. Diz que não, mas não boto muito minha mão no fogo por ele".

"(...) a mulher dorme com um olho aberto $e$ outro fechado".

"A gente não é mais segura nem com o parceiro que a gente pensa que é só da gente, transa só com a gente.(...).”.

Mesmo que desconfiem e/ou não estejam satisfeitas com o companheiro, as mulheres dessa categoria permanecem no relacionamento:

“(...) quando ele fica tomando cerveja com os amigos dele, ele fica assim, tipo meia noite. (...).. Também acentuando novamente já chegou às seis horas da manhã. Então, no início, eu reclamava muito. A gente foi até pra separação. Eu nunca quis casar, sabe. É que eu tive muita dificuldade depois que eu tive minha filha. (...). É muito difícil viver sozinha. (...). Ah, se arrependimento matasse, eu morreria. (...)".

"Ah, a gente briga, mas continua junto. (...)”.

As mulheres se vêem sem alternativas; têm de aceitar a infidelidade, pois dependem, principalmente financeiramente, do companheiro para viver. Além disso, a sociedade ainda discrimina a mulher separada. É como a fala acima: "É muito difícil viver sozinha (...) se arrependimento matasse, eu morreria”. Qualquer relacionamento estável pode tornar-se um campo de interação onde a mulher, em vez de ter uma relação prazerosa, tem de carregar um fardo pesado.

A música Nem Morta, de Sullivan \& Massadas (1994), mostra essa dificuldade que a mulher tem em romper com relacionamentos insatisfatórios:

"Eu só fico em teus braços, porque não tenho forças pra tentar ir à luta

Eu só sigo teus passos, pois não sei te deixar e essa idéia me assusta (...)

Pra você falo tudo, no fim de cada noite, te exponho meu dia

Mas que tola ironia, pois você fica mudo (...)

Sempre que me pergunto quando vou te deixar, me respondo: Nem morta!"

O mais interessante é que as falas dessa música Pra você falo tudo e Te exponho meu dia reflete parte da política de prevenção à AIDS. Estamos constantemente dizendo às mulheres para conversarem com seu parceiro. É como se a mulher tivesse a necessidade de se abrir, se expor, "mas que tola ironia, pois você fica mu$d o$. O que é privado para o homem nem sempre pode ser privado para a mulher.

A passividade e a submissão ao que não agrada ocorrem porque, como salienta Guimarães (1996), as expectativas relacionadas ao modelo de ser mulher, associadas ao estereótipo de esposa compreensiva e conformada com a vida privada de seu companheiro, são atributos ainda preponderantes nas relações conjugais contemporâneas, o que pode dificultar uma abordagem que vise o esclarecimento sobre medidas preventivas para o HIV.

O fato de aceitar a infidelidade do companheiro, de ficar com o mesmo, embora esteja insatisfeita, de aceitar aquilo que não gosta, traz uma conotação de passividade. Por outro lado, elas não se vêm tão passivas assim. Elas se consideram inteligentes ou mais bem informadas do que o homem, e, portanto, é a mulher que tem de tomar frente de tudo.

"A mulher enxerga a maldade de longe. É mais inteligente (risada) que o homem. (...). Meu marido não tem idéia pra nada, coitado (risadas). E na nossa família é assim. Todas as mulheres dominam (...)".

"Nós somos mais inteligente do que eles".

"Por isso que eu digo que a mulher está bem mais informada do que o homem".

Nesse sentido, há um aspecto ativo que não pode ser negado. Não podemos colocar a mulher, simplesmente, no papel de vítima, pois, de certa forma, ela pactua com a situação. Assumindo o papel da mulher que decide dentro de casa e que toma a frente de tudo, assume o poder que lhe é negado em instâncias sóciopolíticas. Usando do único capital que dispõe, que é o controle do espaço doméstico, ela se torna cúmplice e, ao mesmo tempo, depositária da ideologia de dominação de gênero.

\section{Moina (autoconceito das solistas)}

O aspecto de não ter vaidade parece bem peculiar das coralistas, pois, quando comparamos as falas produzidas durante a TDFF, observamos que as solistas incluem, na descrição do desenho, a característica vaidade. Arriscamos dizer que esse aspecto pode ser um dos diferenciais na construção de um perfil de mulher diferente: uma mulher mais politizada, mais crítica e que tende a cuidar mais de si mesma.

Escolhemos o nome Moina para representar essa mulher. Ao pesquisarmos sobre as músicas populares brasileiras, tivemos muita dificuldade em encontrar letras que retratassem mulheres diferentes daquelas de padrão tradicional. Encontramos uma que fala sobre uma mulher chamada Daline Moina, que tem o perfil mais próximo daquele que buscamos. Essa música é cantada por Taiguara (1998), cantor que, como lembra Saffioti (1987), reverencia, em algumas de suas letras, a tão desejada democracia nas relações de gênero.

“(...) E enfrentar o poder!

E renascer... E renascer esse mundo (...) 


\section{Daline Moina me sorriu e amanheceu!}

Confiante, combatente, consciente

Precursora, prenunciante, presidente.

Eu te amo e por ti é preciso ferir, não abrir mão de um ideal

De um mundo igual; de um mundo igual."

Letras sobre mulheres que são conscientes, combatentes e querem enfrentar o poder e fazer renascer o mundo não somente estão praticamente ausentes das músicas brasileiras, como são raras nas imagens difundidas pela mídia televisiva. As imagens de mulher na mídia estão carregadas de estereótipos e "sexismo", pois, na maioria das vezes, elas são mostradas como passivas, submissas, indefesas, características visíveis na figura da Amélia.

\section{José e Ricardão (os companheiros)}

Nas falas das coralistas e solistas, podemos perceber dois tipos de homem: um com características positivas, José, e outro com características negativas, Ricardão. Essas características, muitas vezes, são compartilhadas pelos dois, mas não na mesma intensidade. Entre os dois, há um limite obscuro que não pode ser ultrapassado; caso contrário, o José vira Ricardão e vice-versa. É como se o José fosse o companheiro ideal e o Ricardão o companheiro problemático.

Na verdade, muitas das representações sociais da realidade se formam a partir de dicotomias, como se sempre tivéssemos de ter dois lados de uma moeda: capitalismo/socialismo, pobre/rico, branco/preto; todos qualificados em positivo/negativo. Ao mesmo tempo em que se complementam, os dois lados são distintos. Infelizmente, porém, suas diferenças são mais reforçadas do que sua complementaridade.

De fato, o sistema de papéis sexuais divide a experiência humana. Os homens e as mulheres vivem nessas diferentes metades da realidade, e a cultura reflete isso (Firestone, 1976). Aliás, a própria vida se organiza sobre o par fundamental chamado homem e mulher. Esquecemo-nos, no entanto, que um supõe o outro e que um não existe sem o outro.

Como em todas as dicotomias, o José e o Ricardão têm algo em comum: a mulher como objeto de desejo. Esse desejo é reforçado pelas instituições sociais e é constantemente difundido pela mídia como algo natural e necessário. Ao retratar relações como acontecimentos de um tipo quase natural, eclipsando seu caráter sócio-histórico, a ideologia opera através do que Thompson (1995) chama de reificação. Muitas músicas mostram uma estratégia bem típica da reificação, que é a naturalização, ao enaltecer e reforçar o comportamento mulherengo, "garanhão" e viril masculino. Um exemplo é a letra da música de Bezerra da Silva (1994) que diz: "Vestiu saia tá pra mim... Não sou culpado de haver nascido assim...".

Essa cultura sexual, na qual o homem é o garanhão, o mulherengo, parece prolongar-se indefinidamente em direção ao passado, de tal forma que todo o traço sobre sua origem fica perdido e todo o questionamento sobre sua finalidade é inimaginável. A cultura sexual adquire, então, como alerta Thompson (1995), uma rigidez difícil de ser quebrada, cristalizando-se na vida social, e seu caráter aparentemente a-histórico é reafirmado através de formas simbólicas que, em sua construção e pura repetição, eternalizam o contingente.

Passamos às características compartilhadas por José e Ricardão. Ambos são mulherengos e infiéis:

"Porque homem é homem. É só encontrar em rabo de saia e eles vão. Nem tão. Eles também não são de pedra".

"Eu acho que nem um homem é santo. (...) Tem cara de santo e não é santo".

"Homens também são galinhas, homens casados! (...)”.

Guimarães (1996) assinala que essas características são culturalmente justificadas pela necessária predisposição do homem a conservar a virilidade, a prontidão sexual e a variedade de parceiras como atributos essenciais à formação e à conservação de uma identidade masculina.

Se o comportamento do Ricardão é uma predisposição, sendo, portanto, natural, a Amélia só tem de se resignar e aceitar esse comportamento como algo natural e imutável. Pior, se eles, homens, não representarem esse papel viril, têm a sexualidade questionada.

Quando se indaga dos homens sobre a possibilidade de infidelidade da mulher ou sobre a própria fidelidade, a negação é normal. Enquanto a Amélia confia, ou confia desconfiando, no companheiro, que é infiel, este assume uma postura de total confiança em relação a sua companheira:

“(...) ele confia em mim”.

“(...) ele confia muito em mim também”.

Esse aspecto do comportamento feminino não tem sido levado em conta por muitos profissionais da saúde. $\mathrm{O}$ fato de o homem confiar na companheira pode produzir implicações para o campo da prevenção em saúde, pois não devemos esquecer que a mulher também pode ser infiel. Segundo um estudo realizado na cidade de São Paulo, 1,2\% das mulheres que têm 
um parceiro regular afirmaram ter tido relações com outros parceiros no último ano e 5,8\%, em algum momento de seu relacionamento (Barbosa \& Villela, 1994).

Esse mesmo homem carrega a responsabilidade de cuidar da saúde da companheira:

"Tá cuidando a mulher. É isso que tem que fazer".

"O marido tem que cuidar".

"Tem que pensar na tua saúde e na minha, né”.

A Bíblia já diz: "A mulher não tem poder no seu corpo, mas tem-no o marido” (Bíblia Sagrada, 1997).

Segundo Badinter (1993), desde o surgimento do patriarcado, o homem sempre se definiu como um ser humano privilegiado, dotado de alguma coisa a mais. Ele se julga mais forte, mais inteligente, mais corajoso, mais responsável, mais criativo ou mais racional. Este "mais" justifica sua relação hierárquica com as mulheres ou, pelo menos, com a sua.

Na visão das mulheres deste estudo, a diferença essencial entre o José e o Ricardão é que o último é machão, não é sincero e é muito mais mulherengo e infiel do que o José. O José, como diferencia uma das mulheres, "é um homem mais sério, mais preservado. Não anda com tudo quanto é mulher. Quer dizer, foge do casamento, às vezes dá uma escapada, mas não é sempre. Eu acho que esse aí não é galinha". Ele é sincero, honesto, sentimental, carinhoso, não é machão, pois ele abre possibilidades para o diálogo com a companheira, ouvindo sua opinião e idéias. Talvez, por isso, ele aceite fazer o teste do HIV mais facilmente do que o Ricardão.

\section{Geni (a outra)}

Nas falas, podemos notar claramente uma diferenciação entre dois tipos de mulher: a Amélia, descrita até aqui, e a Geni, ou simplesmente "a outra", o oposto da primeira. Essa mulher é descrita da seguinte forma: mulheres da vida, soltas, trocam muito de parceiros e são oferecidas. Gostam de sair, de se arrumar. Não trabalham e não ajudam na casa:

"Porque a mulher que é galinha anda com todo mundo".

"Vai atrás de qualquer minhoca, ela pega mesmo. Essa é a realidade".

"(...) as mulheres estão se oferecendo hoje em dia. Aonde quer tem uma se oferecendo".

"Tem mulher que não pode ver homem que se atira".

As mulheres entrevistadas acreditam que, nas relações sexuais, a Geni não se protege, pois não usa preservativo, e, quando essas mu- lheres falam sobre isso, falam em um tom de raiva, de indignação, quase como se dissessem “Ela, sim, tem o dever de usar camisinha!”. E, como na visão delas, a Geni não usa preservativo, é vista como se quisesse passar propositalmente o vírus HIV para as pessoas.

Como se vê, a divisão natural entre atores sociais não está presente somente na díade homem-mulher; ela está presente também na dicotomização do gênero feminino, expressa através da figura da Geni. A Geni é aquela mulher de comportamento moralmente inaceitável pelas Amélias. Ela "dá pra qualquer um", como diz a conhecida música Geni e o Zeppelin, de Chico Buarque de Holanda (1979). Embora essa música tenha a intenção de criticar a discriminação contra opções sexuais, pois Geni, na concepção do compositor, era um travesti, no senso comum, Geni transformou-se em um nome figurativo para mulher que não tem parceiro fixo.

Observamos, aqui, a ideologia reforçando as assimetrias sociais, através da fragmentação. Forças de oposição são dirigidas a um alvo específico. A Geni é projetada como uma pessoa ruim, perigosa, que ameaça a moral do casamento monogâmico. Através do expurgo da outra, constrói-se uma inimiga, e é preciso expurgá-la, apedrejá-la, cuspir, se for preciso, e, em muitos casos bater nela, como muitos homens têm feito.

O processo de valorização da propaganda da "Galinha” pelas Amélias reflete o expurgo da Geni. Por outro lado, elas concordam que a Geni seja chamada de galinha, pois, afinal, como diz uma coralista: "vão se dar o respeito se não querem ser chamadas assim”. A desvalorização da Geni é equivalente à desvalorização que sofre a imagem da mulher dentro da propaganda referida, a começar pelo cenário. Enquanto os demais cenários são mais elaborados, a galinha, feita de pano, move-se sobre um fundo formado unicamente por papel pardo amassado, causando uma impressão ao telespectador de descaso e de falta de limpeza. O descaso da sociedade em relação àquelas mulheres, que têm sido julgadas como sujas, é repetido nessa propaganda. Depois, a mulher é retratada como um animal, tendo suas características humanas negadas, como se ela fosse um "bicho", sem sentimentos e sem razão, movida pelos instintos. Usando a metáfora da galinha, justificam-se as desigualdades de papéis: ela pode ser "fartamente consumida" e não amada e "vão bem a qualquer hora", dando margem a desejos sexuais de mão única, no caso, os do homem.

Enquanto as coralistas se identificam com as demais propagandas, pois “a mulher é isso 
mesmo", na opinião delas, obviamente, o mesmo não pode ser dito quanto à propaganda da galinha. Elas não se identificam com essa imagem veiculada, pois as formas simbólicas são construídas de modo que o termo "galinha" seja decodificado pelas receptoras de forma confusa. Algumas não entendem o significado de "galinha"; outras ficam indignadas, pois o termo que deveria, no senso comum, referir-se a uma parte da população feminina (mulheres que variam muito de parceiro) passa a servir ao todo (mulheres em geral). Essa é uma estratégia bem peculiar - denominada de sinédoque -, através da qual a ideologia pode operar para obscurecer, negar ou ocultar relações de dominação de gênero.

\section{AIDS (a doença)}

O tema AIDS ainda é tabu para as coralistas, fazendo com que as pessoas evitem conversar sobre isso. Nessas mulheres, o sentimento presente mais marcante em relação à AIDS é o medo - medo da morte.

Existem alguns medos específicos que são verbalizados, como o medo de ser infectada via tratamento odontológico e o medo relacionado à dificuldade de obter medicação para a doença, que estão relacionados em grande parte com a carência de informação quanto às possíveis formas de infecção pelo HIV e quanto aos direitos que o doente de AIDS vem adquirindo.

Outro aspecto a ser assinalado é que, com o advento da AIDS, tanto as solistas como as coralistas crêem que o comportamento masculino em direção à infidelidade está se alterando:

“(...) os homens, agora, tão bem mais espertos, mais vivos, de olho aberto. (...) Eles tão com medo de pegar AIDS (...)".

“(...) por causa desse negócio aí, os homens gostam mais dessa mulher (...) mais quieta, mais calma (...)".

Se analisarmos essas falas sem um questionamento mais profundo, podemos até pensar que a AIDS está contribuindo para que as relações entre homens e mulheres se solidifiquem. Porém, as mudanças caminham em uma direção obscura e incerta, colocando em risco relacionamentos que envolvam uma real parceria.

A vinculação de estereótipos físicos aos doentes de AIDS, como magreza ou deficiência física, ainda aparece no discurso dessas mulheres. Além desse estigma, o portador do vírus é visto como uma pessoa vingativa, pois contagia os outros propositalmente.

É possível diminuir esses preconceitos? De que maneira? Na visão das mulheres pesquisa- das, o contato com pessoas infectadas, além de tornar a doença real, minimiza o preconceito:

“(...) a AIDS está chegando mais perto da gente, porque, antes, a gente ouvia falar e agora a gente conhece, a gente tem pessoas da família, parentes, que tão com a doença. Então, vai ter que mudar".

“(...). A gente aprende a respeitar o problema dos outros convivendo com isso".

\section{Camisinha (preservativo)}

Confirmando os achados de Loyola (1994), as mulheres participantes na nossa pesquisa pensam que, no geral, as pessoas não estão usando preservativo em suas relações e a possibilidade do uso do preservativo só é aceita quando as pessoas têm relações sexuais pela primeira vez:

"Eu sou casada há anos, uma pessoa só, nunca me separei. E meu marido nunca usou. Nunca usou".

"Eu não sei nem como é que é".

"Geralmente, os homens casados não querem usar camisinha. Eles não usam. É difícil. Pode perguntar aqui para cem mulher. Se uma responder que o marido usa, é difícil. Porque não usa e..."

No entanto, a prática das solistas parece diferir das coralistas quando afirmam usar preservativo:

"Com meu marido foi assim (...). Ele dizia no começo: 'É que nem uma luva. Eu não gosto disso'. Eu dizia: 'É só uma experiência'. E foi. Agora já é natural de usar. Já fica mais normal".

"O meu namorado e eu usamos. Não tem problema".

Nem todas as solistas afirmaram usar preservativo, mas a menção de algumas delas já mostra uma diferença entre mulheres que participam de um projeto de incentivo à prevenção da AIDS e as que não participam, conforme conclui uma solista:

"Nós temos um ideal. Nós somos mulheres trabalhadas. Nós somos mulheres que adquirimos esse saber".

Mas por que, especialmente, as coralistas não estão usando o preservativo, apesar de todo o medo em relação à AIDS? Uma das explicações fornecidas é que altera a relação e o prazer do homem (e não delas próprias). Em vista disso, existe certo desejo de uso por parte da mulher.

Apesar de demonstrarem desejo de usar, existe certa desconfiança quanto à qualidade do preservativo:

"Quem garante que essa camisinha não vai furar? (...)”. 
"O látex é muito [acentuando a palavra] frágil”.

"Mas mesmo tendo validade, pode acontecer, há conseqüências dela rebentar. (...)”.

Um aspecto trazido pelas solistas foi que o homem não sabe como colocar o preservativo:

“Olha, lá em casa, eu que coloco. Por que não há jeito. Ele nunca acerta. Ele não sabe colocar, diz que não consegue".

"Ah, mas não tá dando, porque enrolou aqui do lado, por que o ar não desce [imitando o marido]. Então é assim. Ele não consegue botar".

Certamente, a confiança no companheiro é o primeiro fator visível de interferência na adoção do preservativo. Também o uso do anticoncepcional interfere, já que a camisinha é percebida mais como um contraceptivo do que como proteção às DSTs/AIDS.

Outro fator que interfere na aceitação do preservativo por parte das coralistas é que o uso deste implica diretamente na procriação, o que é visto como um fator extremamente negativo:

"Hein, mas no momento em que todos os casais começarem a usar camisinha, não vai mais existir nem criança, né!".

"Mas se usar camisinha - que eu me refironão vai nascer criança contaminada, nem sem contaminação. E aí como é que vai ser daqui uns anos?".

Por fim, outro fator que podemos destacar é o sentimento de vergonha por parte das coralistas em relação ao preservativo, seja na hora da compra ou na hora do ato de usar per se:

“(...) Você não teria vergonha de chegar numa farmácia e pedir? (...). Seria mais prático o esposo da gente comprar".

“(...). Não é que a gente acha que é feio. Talvez vergonha, sei lá eu (...). Porque tem muita vergonha".

\section{Autocuidado (prevenção)}

O que mais chama atenção nas falas das coralistas é a dificuldade em adotar as estratégias de prevenção enfatizadas pela maioria dos profissionais de saúde ou mesmo em adotar outras práticas alternativas:

"É que a gente nunca pode sentar e conversar. Nunca a gente tentou".

"Ai vai ficar... Eu não ia saber o que fazer [se ele não quiser usar preservativo]. Não ia saber mesmo".

"Tem mulheres que não conseguem [conversar com os companheiros sobre o uso do preservativo]. Até eu não sei se vou conseguir (...)".

Como poderíamos esperar, então, que essas mulheres apresentassem várias alternati- vas de autocuidado? Cuidar de si significa ser independente, e, no caso da mulher, esse aspecto fica exacerbado, visto que ela foi ensinada a ser dependente, pois seu companheiro precisa da dependência da mulher para cumprir seu papel social masculino.

Algumas perguntas surgem dentro desse contexto: O que significa autocuidado para essas mulheres?; Qual a representação da prevenção que elas têm? Parece-nos que a noção de autocuidado e prevenção nas classes populares não vem sendo entendida na sua dimensão cultural. A frase das propagandas "prevenir é a solução" está perdida no espaço das classes populares; não tem nexo e nem pertinência dentro do cotidiano delas. Raras foram as coralistas que mencionaram de que forma estão cuidando de sua saúde em relação à AIDS. Conseqüentemente, foram escassas as alternativas apontadas. Na concepção dessas mulheres, a forma de se cuidar, de se prevenir da AIDS é ir ao médico sempre que podem.

Em um contexto sócio-histórico em que prevalece uma moral cristã apoiada pelo Estado, a mulher Amélia encontra dificuldades em adotar práticas de prevenção propagadas pela mídia e de criar alternativas de autocuidado que sejam viáveis dentro de sua realidade. Não que elas não tenham consciência do risco que correm, pois acreditam na possibilidade (mesmo que remota e necessitando de prova) de infidelidade do companheiro, mas, em virtude de sua baixa auto-estima, não conseguem cuidar de seu corpo como deveriam. Se o marido "está contrariado" e não quer usar camisinha, "o que se há de fazer"? É o fatalismo do dito popular: "Ruim com ele, pior sem ele".

Assim, a Amélia vai construindo sua história silenciosa, opaca, e, em seu corpo, a cultura vai imprimindo suas marcas. Seu corpo submisso, pouco cuidado, revela a cultura na qual ela vive. Esse corpo não é um fato isolado, ele é o corpo social, modelado pelas instituições sociais (Estado, Igreja, etc.). O corpo físico e o social se fundem, e o primeiro se modifica em função do segundo. Como diz Gonçalves (1990), cada corpo expressa a história acumulada de uma sociedade, que nele marca seus valores, suas leis, suas crenças e seus sentimentos, que estão na base da vida social.

É muito comum associarmos a falta de cuidado com si mesmo a "não ir ao médico". A propaganda da Hebe aponta como alternativa “ir ao médico sempre”. A mulher que não vai ao médico é comumente censurada por não cuidar de seu corpo. Mas o Estado não tem propiciado recursos e oportunidades para que o capital "saúde" seja distribuído justamente. Po- 
demos aventurar a hipótese de que a falta de autocuidado do corpo social relaciona-se à falta de cuidados por parte do Estado para com o cidadão. O Estado não tem atendido às necessidades do povo na área da saúde. Pior, o Estado tenta assumir o controle sobre o corpo social: "Ponha camisinha!"; "Converse com seu parceiro!"; "Não use drogas!”; "Vá ao médico sempre!" Esses imperativos estão fadados ao fracasso, pois o corpo individual encontra subterfúgios para resistir ao controle social.

O Estado assume um compromisso com o corpo da mulher, mas não consegue cumpri-lo. Veicula na mídia uma estratégia de prevenção que arranca das pessoas a capacidade de autocuidado, contribuindo para que a mulher desconheça o próprio corpo. É mais seguro, em termos de manutenção do status quo, se o Estado continuar responsável pelo corpo feminino, mesmo que isso implique um pseudocuidado. Como vamos querer, então, que a população assuma a responsabilidade de autocuidado? Como vamos encontrar meios viáveis de prevenção dentro de uma cultura específica se o Estado também não produz alternativas em meio ao caos e se as formas simbólicas das propagandas de prevenção da AIDS repetem a política do Estado? O abandono do cuidado com si mesmo corresponde ao abandono da nação pelo Estado.

Outras alternativas de autocuidado mencionadas pelas solistas e coralistas foram: propor que o companheiro use preservativo nas relações com a "outra"; solicitar ao companheiro que faça o teste de HIV; e abster-se temporariamente de sexo.

\section{Propagandas}

De modo geral, as coralistas valorizam positivamente as formas simbólicas da maioria das propagandas de prevenção da AIDS, classificando suas mensagens como boas e relevantes para as mulheres, conforme verbaliza uma delas: "Se não existissem essas propagandas, acho que teria muita gente contaminada". Contudo, acreditam que elas não despertam os homens:

"Eles nem prestam atenção nas propagandas".

"Só [convence a usar preservativo] se fizer pros homens. Pros casados".

"Ajudam. Ajuda bastante. Mas tem homem que acha que é bobagem. Não desperta os homens".

Gostar das propagandas não significa que as entrevistadas sejam passivas em relação às formas simbólicas, pois estas são interpretadas a partir das especificidades culturais das pri- meiras. Enquanto as propagandas dizem "Você tem que usar camisinha”, elas rebatem: "O que adianta! A gente sabe que tá matando, mas as propagandas não convencem os homens a usar camisinha" ou "A propaganda dela [da Hebe] tá certa, que é pra conversar com o marido que tá em casa, mas como?".

O maior impacto causado pelas propagandas é o medo, que pode estar ligado à percepção que elas têm da doença, como vimos antes:

"Pela minha, medo. Medo, (...)".

"A gente fica até com medo de pegar AIDS, ainda mais com as propagandas que a gente vê. Tem sempre medo. Dá medo essas propagandas".

O discurso das mulheres mostra que elas acreditam que a mulher seja mesmo o que estão mostrando:

“(...) É a pura realidade isso ali, tudo o que eles falaram é a pura realidade”. do]".

"Acho que a mulher é isso mesmo...[refletin-

"Eu acho que elas são assim mesmo, porque aqui mesmo você tá tendo uma prova”.

"(...), praticamente ninguém usa camisinha aqui. Então, são realmente aquilo ali. Confiam”.

Elas gostam, em especial, das propagandas que são classificadas como sérias, que falam direta e abertamente, que passam mensagens sobre prevenção, do tipo "use camisinha”, que estimulam o diálogo ou que explicam sobre as formas de infecção.

A propaganda da "Hebe" foi, sem dúvida alguma, a que recebeu críticas mais positivas:

"Ela vai direto ao assunto. A pessoa não tem que fazer muito rodeio".

"E pra homem também (...)".

"É uma mulher que tanto pobre como rico assiste. (...). Tá preocupada com o pobre, com o rico, com o branco, com o preto".

Do ponto de vista de produção e codificação de mensagem, podemos dizer que os produtores dessa forma simbólica foram extremamente perspicazes, recorrendo ao que Thompson (1995) chama de valorização cruzada. Ao escolherem a atriz Hebe Camargo - a qual possui alto valor simbólico -, tiveram a chance de aumentar a possibilidade de promoção de atitudes positivas frente à prevenção da AIDS.

Por outro lado, embora também tenham apreciado a propaganda da Hebe, as solistas salientam que propagandas que falam sobre a necessidade de usar camisinha deveriam ser feitas por atores ou atrizes que tenham maior probabilidade de realmente usar preservativo.

Na propaganda da Hebe, em seu discurso, ela acentua o pronome "você": "E você [aponta para a telespectadora] e seu parceiro podem cui- 
dar disso juntinhos..., você tem que usar camisi$n h a "$, como se ela não conseguisse cuidar disso juntinho com o próprio parceiro e como se ela não tivesse também que usar preservativo.

As solistas percebem essa dissonância entre o discurso e a prática da apresentadora: “ $A$ Hebe (...) pra transmitir sobre camisinha fica estranho"; "Não fica verdadeiro".

Aqui, o princípio de marketing que diz que comunicadores que são mais populares e que têm maior credibilidade são mais persuasivos do que os que não são (Stephan \& Stephan, 1985) parece perder sua força. De nada adianta escolher uma atriz tão popular como a Hebe, se a mensagem divulgada não soar verdadeira.

Cabe assinalar que existem diferenças entre os objetivos de uma proposta de marketing que tenta persuadir alguém a tomar um refrigerante ou a comprar um automóvel e uma campanha que visa prevenção no campo da saúde pública - marketing social. Sabemos que, na publicidade, o uso de imagens não muito claras pode ser um recurso extremamente positivo, mas o discurso das coralistas mostra que, na área da saúde, esse recurso não é assimilado de forma positiva.

No marketing social, a intervenção é desenvolvida a partir de uma base sólida das teorias da comunicação, mas vai além, pois, como diz Wallack (1990), ele também se apóia nas teorias psico-sociais.

Quanto às propagandas, a do "carnaval" foi avaliada positivamente e as dos jornalistas Eliakim Araujo e Leila Cordeiro, embora pouco lembradas e comentadas pelas mulheres, também foram consideradas boas.

A propaganda do "Pega-Não Pega" recebeu os dois lados da crítica:

“(...), a explicação maior acho que é a mais importante. As maneiras, os métodos, pela transfusão, pelo anal, o que pega, o que não pega. (...). Como transmitir a AIDS".

"É pra gente não rejeitar também, quando chega numa casa e tem um aidético, a gente pode ficar com nojo de tomar um copo d'água. Aquilo ali é uma explicação boa,(...).”.

"E aquela propaganda mostrou de como pega, se pega desse jeito, daquele. Ali mostrou bem. Aquela propaganda foi bem explicada, bem bolada".

Outra parte dessas mulheres questiona o conteúdo desta propaganda:

"Eu tenho certeza que naquela propaganda do Pega-Não Pega não tem tudo. O dentista não tá ali. E pega até hepatite".

"Eu tenho medo porque nem tudo que diz ali é verdade. Eu tenho medo".

"Elas não são confiáveis não".
Para aquelas que têm mais informações acerca da AIDS, no caso as solistas, as deficiências dessa propaganda aparecem mais nitidamente:

“(...). Propaganda muito besta. Não tem nada sem camisinha. Sexo vaginal pega só se for sem camisinha! [tom de indignação]. 'Sexo anal sem camisinha. Pega'[Imitando a propaganda]. Nós já discutimos aquele dia. Tá errado”.

“(...). Pega ou não pega. É só isso que diz (...). Não diz direito.(...). Não tá certo. Tinha que explicar melhor. Porque não tem ali 'Use camisinha'? Sem camisinha é que pega. É uma coisa sem nexo".

"Se meu namorado usa droga injetável pega AIDS [tom irônico]. Tá errado. Pega se dividir a seringa".

Resultado, tanto as coralistas quanto as solistas não se incluem como audiência-alvo dessa propaganda:

"Pra nós, eu acredito que não seja [essa propaganda]. (...)”.

"Essas propagandas são pra os ignorantes".

Outra propaganda criticada e que gerou sentimentos de ambivalência foi a denominada "Eu confio":

“(...) eu não concordo com as mulheres da propaganda que dizem que confiam no marido]".

“(...) ali na televisão, as mulheres falam uma coisa e na realidade elas fazem outra. (...). Muitas vezes, elas querem dizer uma coisa ali, (...). Elas querem dizer que elas usam camisinha ou se previnem. Mas, no fundo, chega nessa hora, elas não fazem isso. (...). Então, isso eu acho errado".

Elas também não gostaram da propaganda da galinha, pois se sentiram comparadas a uma galinha:

"Parece assim que tudo que é mulher vai pegar AIDS ou anda com tudo que é homem. Não é assim na verdade. (...)".

"Mas eles tão ofendendo a mulher, porque nós não somos todas assim".

"Acho um absurdo aquilo ali. Isso quer dizer que todo mundo come galinha? Uma ofensa para a mulher... acho um absurdo... uma falta de respeito... Só as mulheres fazem e têm AIDS?".

O mais interessante é que a maioria concorda que a mulher seja chamada de galinha, desde que a elas próprias não sejam essa galinha. A diferenciação Geni-Amélia deve ficar clara na propaganda para que elas não se sintam ofendidas.

Além da propaganda da galinha reforçar as relações de dominação, seja através de estratégias como expurgo da outra ou uso de metáfora, o codificador dessa forma simbólica peca 
por usar um termo genérico para se referir a um público-alvo específico, em vez de ser direto e claro, burlando um dos princípios do marketing social, que preconiza mensagens claras (Kotler, 1978).

Foi observado, também, que existe uma falta de entendimento acerca das mensagens em geral e dificuldade de fixar o conteúdo de algumas propagandas, por parte das coralistas:

"Eu sou bem analfabeta. Eu não entendo muito dessas propagandas. Eu não conheço”.

"Falam muito ligeiro".

"As outras não chamaram muito a atenção... aquela da guria... acho que foi muito rápido, acho que é uma coisa meio esquisita de entender. Ela não fala direito o que é AIDS, (...)”.

A ambivalência, a discordância e a falta de identificação com algumas imagens não levam estas mulheres a enxergar essas propagandas como discriminatórias:

"Mulher branca, negra. Acho que a propaganda tá falando assim, que AIDS não tem limite, pega em qualquer pessoa, qualquer mulher. Não importa a cor, não importa a raça, não importa nada. Aquela propaganda quis mostrar isso, eu acho".

É justamente sobre esse aspecto que as solistas diferem radicalmente das coralistas. Enquanto as primeiras parecem não enxergar as propagandas como discriminatórias, o discurso das solistas mostra que elas percebem as relações de dominação de gênero:

"Quando colocam um homem, é sempre naquela posição [Coloca seu corpo em posição bem ereta]. Quando é mulher, não. É bem burra. É mulher, é galinha [afinando a voz, em tom indignado]. Quando é homem, já é uma conversa de homem pra homem, direta".

"A mulher e a droga ficam como a mesma coisa. Fala em droga, fala em mulher".

"Porque parece que a mulher já é tão sofrida, tão discriminada, daí faz uma campanha sendo discriminada numa campanha, passando por burra na campanha também".

"Como se ela vive no mundo das caverna, né? “.

"É a Amélia, né?! ".

Extremamente ligada à consciência de gênero, está a consciência de classe e de raça, que aparece nitidamente nas falas delas:

“(...) só a pobre que é burra, só a pobre que só sabe fazer filho, só a pobre que não usa camisinha. Tem muita mulher de boa vida se contaminando por ignorância. Mas, ali no comercial, só mostraram as pobres".

“(...). Lá no estúdio, tava a Hebe, o Eliakim, etc. e tal. Quando eles desceram para o barraco, pra zona, apareceu só nega".
“(...). O pessoal de dinheiro, de bens, são bem hipócritas, (...). Porque eles não falam da realidade deles, por isso eles buscam mais o pessoal simples".

“(...) é muito fácil expor o pobre, entendeu. De colocar o pobre na linha de frente. (...)”.

"Também é só nega".

"Porque só a negra?".

As formas simbólicas são construídas como se ser pobre significasse ser desprovido de saberes: as pessoas ricas sabem como se cuidar, como se proteger; as pessoas pobres só sabem fazer um monte de filho. Se isso é só o que elas sabem, alguém tem de dizer a elas como se cuidar e, nessa trama de mensagens, a ideologia vai operando e estabelecendo quem domina quem.

Independentemente da existência ou não de uma consciência crítica mais acirrada, todas as mulheres trouxeram algumas sugestões e saídas para a melhoria das propagandas.

Quanto à construção das mensagens das propagandas, as solistas e coralistas salientam a necessidade de objetividade, clareza e simplicidade do conteúdo.

Com relação ao público-alvo, elas sugerem que se elaborem propagandas para os homens:

"Tinha que falar mais pros homens. Pode ver. Na maioria das propagandas tá a mulher. E o homem? Onde é que o homem tá nessa história?".

"Então, assim como tem reunião pra nós no colégio, tem que ter reunião pros pais. Tem que fazer propaganda pros pais também. Exigir o pai, né?"

As solistas sentem que as propagandas precisam mudar quanto aos seus aspectos discriminatórios em relação a grupos étnico-raciais ou classes sociais:

"Acho que tinha que ter branca, preta, amarela"

"Japonês. Tinha que variar. Por níveis mais altos, mais baixos. A imagem é só de mulher pobre e de cores, só mulher mais velha. Tem que mostrar mulher branca, de alta sociedade".

"Tinha que ter não só cearense, tinha que ter mistura de cor, de raça, de tudo quanto tipo de mulher".

"Tem que por pessoas de alto nível, pessoa de estudo. Está tudo escondido".

"Nas campanhas tem que mostrar que o rico pega também".

Também sugerem a presença de homossexuais, bissexuais, mulheres usuárias de drogas, crianças e jovens, em vez de focalizarem só a mãe. Quando o público-alvo envolver mulheres-mães, argumentam que se deve dar atenção à questão da amamentação. 
Outra sugestão apresentada foi a de que se deve falar mais do preservativo, mostrando, inclusive, como colocá-lo.

O papel do "outro" e da "outra” também deve estar presente nas propagandas:

"Mas, eu acho que, no caso, teria que falar na outra, no outro também".

"Só acho que tinha que ser mais direto. Mostrar ele aparecendo com uma outra. (...)".

"Eu acho que esse negócio de troca de parceiros, eu acho que tinha que ser mais comentado. Pras pessoas não trocarem de parceiro. Porque eles só falam mais, praticamente, da camisinha".

Para encerrar as sugestões, elas pensam que as propagandas têm de mostrar a realidade como ela é, mas, em vez de centrarem-se em aspectos discriminatórios, que perpetuam as relações de dominação de gênero, elas têm de mostrar as qualidades das mulheres:

"Tem que mostrar a realidade, mas que ela está fazendo alguma coisa pra se prevenir. Não digo que não tem que mostrar a Amélia. Tem que mostrar a Amélia [dizendo]: 'Meu marido usa droga, mas eu uso camisinha'. Isso que a propaganda devia dizer. (...) mostrar a Amélia consciente".

"Tem que mudar e mostrar a mulher forte".

"Tem que mostrar aquela realidade, mas mostrar que ela tá fazendo alguma coisa pra se prevenir".

“(...) só mostra mulher na vila, no meio dos lençóis, com um baita dum barrigão. Essa idéia aí... tem que deixar essa idéia prá trás. E tem que tocar pra frente".

“(...) deveriam colocar elas sentadas trocando idéias com outros, com agentes de saúde, doutrinando elas pra saber as formas de contágio, se o marido é ou não... tentar abrir a cabeça delas, dando um amplo espaço pra elas poderem começar a se desenvolver, poderem ter um pensamento mais aberto".

O que elas estão dizendo é que a mulher não é tão passiva assim; ela faz parte do processo e, como parte ativa, precisa, também, ser mostrada ativa nas propagandas. No recorte abaixo, elas mostram como poderíamos alterar a imagem de uma mulher passiva:

"Teve aquela do carnaval, agora já tiraram, que ele tira a camisinha do bolso e cai... aí ela ajunta a camisinha. Podia ser uma outra propaganda. Ele tirando do bolso e dando pra ela.
No caso o homem dizendo, "Você coloca" ou "Você põe". "Me ajuda..."

\section{Considerações finais: repensando o próximo show}

Seria necessário dar outro rumo às vozes da televisão. Oxalá tivéssemos uma fórmula mágica capaz de romper com o movimento da ideologia e das relações de dominação de gênero, mas não temos respostas concretas para isto, pois modificar o modo como são construídas as formas simbólicas implica em movimentarse contra todo um sistema. Será necessária uma revolução no modo como as formas simbólicas das propagandas de prevenção à AIDS são construídas, e essa revolução só será possível na medida em que as relações de dominação deixarem de ser veiculadas como algo natural e imutável.

Em um mundo contemporâneo, onde, em um crescente contínuo, as imagens da mídia despertam fascínio e interagem com as culturas, precisamos aprender a ouvir, interpretar e, também, construir criticamente as diferentes linguagens visuais produzidas pela mídia.

É necessário que desconstruamos as dicotomizações presentes na mídia (e em outras instituições) para que possamos pensar sobre as questões de gênero e conseguir fazer prevenção. Este elemento binário está presente não só no sentido masculino-feminino, mas no feminino-feminino, representado pela AméliaGeni e, também, no masculino-masculino, representado pelo José-Ricardão.

A sexualidade tem sido abordada pela metade nas propagandas: falam com as mulheres e não com os homens; reclamam fidelidade e fecham os olhos para a infidelidade. Trata-se do desligamento de partes que são inseparáveis.

Embora reconheçamos que haja dificuldades no abandono desse interjogo de dicotomias, acreditamos que tais princípios podem ser desconstruídos através do desvelamento e ressignificação da lógica da ideologia binária dos sistemas tradicionais de pensamento. Segundo Derrida (1978), esse processo implicaria deslocar os termos, para demonstrar que cada um está presente no outro, bem como evidenciar que as oposições são histórica e lingüisticamente construídas. 


\section{Agradecimentos}

Artigo baseado em Dissertação de Mestrado apresentada no programa de Psicologia Social e da Personalidade, da Faculdade de Psicologia, da Pontifícia Universidade Católica do Rio Grande do Sul (PUCRS), financiada pela CAPES e orientada pelo Dr. Pedrinho A. Guareschi, ao qual devo os mais sinceros agradecimentos pelo apoio, orientação e carinho oferecidos ao longo do percurso dessa pesquisa. Também agradeço as contribuições feitas por Sandra M. Nora.

\section{Referências}

ALVES, A. \& LAGO, M., 1994. Ai que saudades da Amélia. In: Leve Meu Samba (Ataulfo Alves), CD, Rio de Janeiro: Sigla.

ANG, I., 1990. Desperately Seeking the Audience. London: Routledge.

BADINTER, E., 1993. XY. Sobre a Identidade Masculina. Rio de Janeiro: Nova Fronteira.

BARBOSA, R. M. \& VILLELA, W. V., 1996. A trajetória feminina da AIDS. In: Quebrando o Silêncio: $M u$ lheres e AIDS no Brasil (R. Parker \& J. Galvão, orgs.), pp. 17-32, Rio de Janeiro: Relume-Dumará/ABIA/ IMS/Universidade do Estado do Rio de Janeiro.

BERGER, A. A., 1995. Media Research Techniques. Newbury Park: Sage Publications.

CABRUJA, T. \& PUJAL, M., 1993. Dimensiones Psicosociales de la Educación: Psicología de la Comunicación. Sevilla: Eudema.

DEBUS, M., 1986. Manual para Excelencia en la Investigación Mediante Grupos Focales. Washington, D.C.: Porter Noveli.

DERRIDA, J., 1978. Writing and Difference. Chicago: University of Chicago Press.

EISLER, R., 1996. Communication, socialization and domination. In: Women Transforming Communications. Global Intersections (D. Allen, R. R. Rush \& S. J. Kaufman, eds.), pp. 28-39, Thousand Oaks: Sage Publications.

FIRESTONE, S., 1976. A Dialética do Sexo: Um Manifesto da Revolução Feminista. Rio de Janeiro: Labor do Brasil.

FISKE, J., 1990. Television Culture. London/New York: Routledge.

GONÇALVES, M. S. A., 1990. Sentir, Pensar, Agir. Corporeidade e Educação. Rio de Janeiro: Papirus.

GUBA, E. \& LINCOLN, Y. S., 1981. Effective Evaluation. San Francisco: Jossey-Bass.

GUBA, E. \& LINCOLN, Y. S., 1985. Naturalistic Inquiry. Beverly Hills: Sage Publications.

GUIMARÃES, K., 1996. Nas raízes do silêncio: A representação cultural da sexualidade feminina e a prevenção do HIV/AIDS. In: Quebrando o Silêncio: $M u$ lheres e AIDS no Brasil (R. Parker, \& J. Galvão, orgs.), pp. 89-113, Rio de Janeiro: Relume-Dumará/ABIA/ IMS/Universidade do Estado do Rio de Janeiro.

HOLANDA, C. B., 1979. Geni e o Zepelin. In: Minha História. O Melhor de Chico Buarque (Chico Buarque), CD, São Paulo: Poligram.
KITZINGER, J., 1994. Focus groups: Method or madness? In: Challenge and Innovation: Methodological Advances in Social Research on HIVIAIDS (M. Boulton, ed.), pp. 159-175, London: Taylor \& Francis.

KOTLER, P., 1978. Marketing para Organizações que não Visam Lucro. São Paulo: Atlas.

LOYOLA, M. A., 1994. AIDS e Sexualidade: O Ponto de Vista das Ciências Humanas. Rio de Janeiro: Relume-Dumará/Universidade do Estado do Rio de Janeiro.

MINAYO, M. C. S., 1992. O Desafio do Conhecimento: Pesquisa Qualitativa em Saúde. São Paulo: Editora Hucitec/Rio de Janeiro: ABRASCO.

ROSO, A., 1997. Grupos focais em psicologia social: Da teoria à prática. Psico, 28:155-170.

ROSO, A., 1998. Comunicação. In: Psicologia Social Contemporânea (M. G. C. Jacques, M. N. Strey, M. G. Bernardes, P. A. Guareschi, S. A. Carlos \& T. M. G. Fonseca, orgs.), pp. 146-158, Petrópolis: Editora Vozes.

SAFFIOTI, H. I. B., 1987. O Poder do Macho. São Paulo: Moderna.

SANCHO, L., 1993. Sexismo y Embarazo: Análisis de "nuevo Fiat Tipo". Nacido Seguro. Trabajo propuesto en lo XII Cursos de Verano de la Universidad del País Vasco: La transmisión de valores sexistas en los medios de comunicación. San Sebastian: Universidad del País Vasco.

SILVA, B., 1994. Vestiu saia tá pra mim. In: Leve Meu Samba (Ataulfo Alves), CD, Rio de Janeiro: Sigla.

STEPHAN, C. W. \& STEPHAN, W. G., 1985. Two Social Psychologies. Homewood: The Dorsey Press.

SULLIVAN, M. \& MASSADAS, P., 1994. Nem morta. In: Sullivan e Massadas ao Vivo (Michael Sullivan \& Paulo Massadas), CD, São Paulo: Som Livre.

TAIGUARA, 1998. Mona me Sorriu. <http://yahoo/lyrics/ music $>$.

THOMPSON, J. B., 1995. Ideologia e Cultura Moderna: Teoria Social Crítica na Era dos Meios de Comunicação de Massa. Rio de Janeiro: Editora Vozes.

WALLACK, L., 1990. Improving health promotion. In: Mass Communication and Public Health. Complexities and Conflicts (C. Atkin \& L. Wallack, eds.), pp. 147-163, Newburry Park: Sage Publications.

WINSHIP, J., 1996. Sexuality for sale. In: Culture, Media, Language (S. Hall, D. Hobson, A. Lowe \& P. Willis, eds.), pp. 217-223, London: Routledge. 